\title{
Selection of Optimum Process Parameters in High Speed CNC End-Milling of Composite Materials Using Meta Heuristic Techniques - a Comparative Study
}

\author{
Vikas Pare - Geeta Agnihotri - Chimata Krishna* \\ Maulana Azad National Institute of Technology, Bhopal, India
}

\begin{abstract}
The machining of aluminium metal matrix composites in CNC high speed conditions is significant because such composites have diverse applications in the aeronautics industry. Because that industry requires high quality outcomes, the prediction of surface roughness, which depends on input process parameters, assumes significance in the maintaining quality of products. Even though many researchers have worked in the area of conventional machining, very few of them have explored optimization techniques, such as teaching-learning-based optimization (TLBO) and gravitational search algorithms (GSA) in high speed environments. In this research, an attempt is made to determine the optimum machining conditions for the end-milling of composite materials using GSA. Input process parameters, such as cutting speed, feed, the depth of cut and the step-over ratio are taken as independent variables, and surface roughness is taken as dependent variable. Experiments were conducted on $\mathrm{Al}_{2} \mathrm{O}_{3}+\mathrm{SiC}$ metal matrix composite by considering selected variations in the input process parameters. Surface roughness is measured in each of cases, and the required data is obtained for further analysis. An empirical relationship is established between dependent and independent variables in the form of linear and non-linear regression equations, and the results are analysed. The results showed that GSA gives better results for surface roughness when compared to the genetic algorithm, simulated annealing and TLBO methods. An additional set of experiments was conducted to validate the results obtained.
\end{abstract}

Keywords: high-speed machining, metal matrix composite, surface roughness, gravitational search algorithms, teaching-learning-based optimization

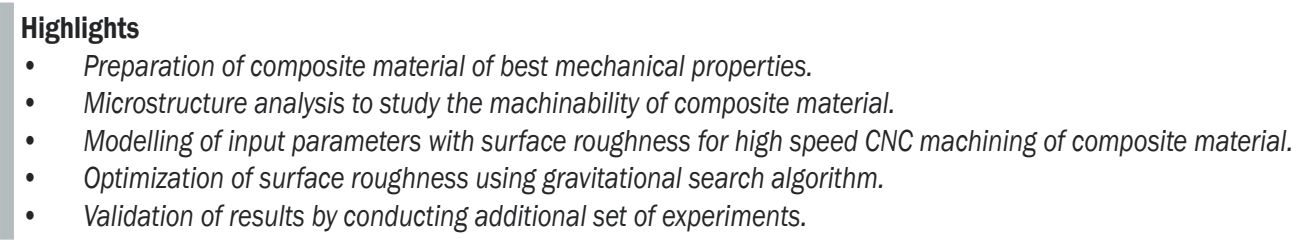

\section{INTRODUCTION}

High speed milling (HSM) has assumed importance in recent years due to increased demand for quality, productivity and cost reduction in manufacturing [1]. HSM can be used mostly for relatively softer materials and the production of components in mass scale. The machining of the aluminium metal matrix composite is a significant high-speed milling application. This technology has wide application in the aeronautics or aerospace sectors, and the moulds and die industry [2] and [3].

A metal matrix composite is made by combining at least two constituent parts, one of which must be a metal. Normally, other constituents may be different materials, such as ceramics or organic compounds. In this paper, silicon carbide is used as second constituent, as it reduces the cost of resultant composites. In order to obtain the required properties in the matrix alloy, the reinforcement material, the volume of the reinforcement, location and the shape of the reinforcement and fabrication method can all be varied [4]. The objective involved designing a metal matrix composite material mainly by adding the desirable attributes of metals and ceramics. The steps involved with castings of metal matrix composite are as follows:

- Melting the aluminium metal with 5, 10, 15 and $20 \%$ on a mass fraction basis;

- Pouring it into an already prepared mould or cavity, which has the shape of the desired component;

- Cooling and solidifying the molten metal in the mould; and

- Removing the solidified component from the mould and cleaning it properly.

The machinability of aluminium composites is considerably high in comparison to other materials. Whether the material is stable after a high-speed milling operation is performed on it needs to be studied; i.e. the structure of material needs to be checked after machining. Surface roughness is a measure of the technological quality of a product and has influence on manufacturing cost and the quality of the product. Therefore, industries always choose to maintain the good quality of the machined 
surface. The surface roughness and material removal rate considerably change with the variation of cutting process parameters; thus, the appropriate selection of process parameters has significant role in the prediction of the surface finish and material removal rate in the high-speed end-milling process. Therefore, it needs to be studied in the context of the machining of aluminium composites as well in high-speed machining conditions.

Theoretical models have been proposed for the selection of process parameters by earlier researchers [5] to [7]. However, they do not yield good results under all the conditions of experimentation. As a result, machine operators generally use trial-anderror approaches to set up milling machine cutting conditions in order to achieve the required surface roughness. These methods are not productive and are extremely time consuming. Therefore, establishing empirical relations between output parameters, such as surface roughness and input process parameters, and then optimizing the output parameters will result in reasonably accurate results in HSM. However, there are many problems associated with the optimization of large-scale problems, such as multimodality, dimensionality and differentiability. Conventional approaches, e.g. linear and dynamic programming, etc., are not efficient in solving non-linear objective functions. Therefore, to develop efficient and effective optimization techniques is a matter of great urgency. Research is being conducted in this field and natureinspired meta-heuristics optimization approaches are considered better than the traditional techniques, and thus are prominently used.

One of the most efficient and effective optimization techniques reported is the gravitational search algorithm (GSA), which was developed by Rashedi et al. [8] and is based upon the gravitational and motion laws of Newton, where by every particle is considered an agent in the universe. The particles attract each other with a force that is dependent on their masses and distances. An optimization method, such as teaching-learning-based optimization (TLBO), is also used for obtaining global solutions instead of local optimal solution for continuous non-linear functions. The TLBO method works on the philosophy of teaching and learning [9]. These methods may not offer the best solutions to all types of problems. Some of them yield their best results for specific cases and thus other methods result in optimum values for other types of problems. Therefore, it is important to consider a few soft computing techniques for applications in order to know which best suits the given problem.
In this work, the structure of casting of aluminium silicon carbide is tested for uniformity of distribution, by using an electron microscope before machining. Experiments were conducted on this material using a CNC high-speed machine by varying four selected input parameters: cutting speed, feed, depth of cut and step over ratio. The structure of material is also tested, using an electron microscope after machining.

The surface roughness is measured using Taylor Hobson surface roughness tester (Surtronic $3+)$ for each of the forty selected combinations of input parameters. The surface roughness tester has a traverse speed of $1 \mathrm{~mm} / \mathrm{s}$; the measurement unit is $\mathrm{mm}$ present by the dual in-line package (DIP) switch, deselected via the menu; its cut-off values are 0.25 , 0.8 , and $2.5 \mathrm{~mm}$; its traverse length $1 / 4$ Lambda $+n$ Lambda $(n=1,3,5,10$ or $25.4+0.2 \mathrm{~mm}$ at $0.8 \mathrm{~mm}$ cut-off); its parameters are $R_{a}, R_{q}, R_{z}$ (DIN), $R_{y}$ and $S_{m}$; its calculation time is less than reversible time or $2 \mathrm{~s}$, which ever is longer. An empirical relationship between surface roughness and the input parameters is established using the MINITAB software package. The empirical equations thus obtained are optimized using GSM, TLBO, simulated annealing (SA) and genetic algorithm (GA) methods, and the results are compared.

This paper is organized as follows: in addition to the introduction in this section, a brief review of literature is given in Section 1. Experimental set up and conduction of experiments is explained in Section 2 , and the results obtained and analysis are explained in Section 3. The conclusions drawn are given in Section 4.

\section{LITERATURE REVIEW}

The results of some of the researchers who worked on conventional machines and high-speed $\mathrm{CNC}$ machines by varying selected input parameters are presented in the following section. The literature includes only soft computing applications and meta-heuristic methods in the analysis of machining parameters for composite materials.

\subsection{Composite Material}

Pathak et al. [4] presented the preparation of an aluminium silicon carbide composite. They have also given a detailed discussion about the microstructure and its different mechanical properties. Neelima Devi et al. [10] studied the characterization of an aluminium silicon carbide composite. In their paper, tensile strength experiments were conducted by varying mass 
fraction of $\operatorname{SiC}(5,10,15$, and $20 \%)$ with aluminium. Palanikumar and Karthikeyan [3] investigated the factors influencing the surface roughness on the machining of $\mathrm{Al} / \mathrm{SiC}$ particulate composites, using tungsten carbide tool inserts (K10). Dabade et al. [11] studied the surface integrity as a function of process parameters and tool geometry by analysing cutting forces, surface finish, and microstructures of the machined surfaces on $\mathrm{Al} / \mathrm{SiC} / 10 \mathrm{p}$ and $\mathrm{Al} / \mathrm{SiC} / 30 \mathrm{p}$ composites using cubic boron nitride $(\mathrm{CBN})$ inserts. Basheer et al. [12] presented a model to predict the surface roughness in precise machining of metal matrix composites, using PCD tools with respect to the size and volume of reinforcement, tool nose radius, feed rate, and the depth of cut. Very few of them worked with composites in HSM conditions and checked the stability of composite by testing the microstructure after machining.

\subsection{Conventional Machining}

Some researchers used statistical methods for analysing the relationships between surface roughness and selected input parameters. Aluminium metal matrix composite was used by Seeman et al. [13] whereas $\mathrm{LM} 25 \mathrm{Al} / \mathrm{SiC}_{\mathrm{p}}$ composite was used by Arokiadass et al. [2]. Both used surface roughness and tool wear as output variables in their studies. They used RSM for establishing the relationship between input and output variables and conducted statistical analysis. Seeman et al. used machining time $(t)$, estimated flank wear $\left(V_{B} \max \right)$ and surface roughness $\left(R_{a}\right)$ in addition to the three parameters used by most of the researchers.

Other researchers used soft computing techniques for analysis. The application of the GA method is the most common method found in the literature. Bhushan et al. [14] studied the $7075 \mathrm{Al}$ alloy $\mathrm{SiC}$ composites and applied the GA technique to optimize the machining parameter in turning operations. Rai et al. [15] studied the multi-tool milling and estimated the machining time by applying GA techniques, taking axial depth of cut, radial immersion, feed rate and spindle speed as input parameters. Del Prete et al. [16] studied the flat end-milling process with feed, depth of cut, radial engage and speed as input parameters. Xu et al. [17] estimated various output parameters, such as cutting force, tool life and machined surface roughness by taking feed rate, depth of cut and cutting width as input parameters. Saffar and Razfar [18] estimated cutting force in the end-milling process by taking speed, feed rate and radial rake angle as input parameters. Alam et al. [19] predicted the surface roughness by considering speed, feed rate, and depth of cut as input parameters. They applied both the GA and quadratic prediction models to optimize the machining process parameters for the minimum surface roughness.

Rao et al. [9] proposed TLBO for the optimization of mechanical design problems. In their paper, he compared this technique with other techniques and proved TLBO to be best. Rao et al. [5] also used TLBO techniques for non-linear large scale problems and compared the results with those obtained by other techniques such as GA, particle swarm optimization (PSO) and artificial bee colony ( $\mathrm{ABC}$ ) techniques, and obtained the best results.

There is no specific heuristic algorithm suitable for all types of problems. The methods used may result in better solutions under specific conditions. $\mathrm{Li}$ et al. [20] developed models to estimate the cutting force, tool life and surface roughness. They applied PSO to improve the result. Pare et al. [21] used speed, feed, the depth of cut and the step-over ratio as input variables and optimized surface roughness using PSO. Unlike PSO, in which the two best positions decide the direction of search, GSA uses the weight of all agents for finding new search directions. Zubaidi et al. [22] applied the GSA for the optimization of cutting conditions for end-milling Ti6A14V alloy and obtained results that were proved to be better in comparison to GA and PSO techniques.

In addition to the above application of heuristic search-based algorithms, some researchers combined selected algorithms (hybrid) and made attempts to apply them in different contexts. Farahnakian et al. [23] studied end-milling with PSO combined with a neural network (NN) algorithm to predict surface roughness and cutting forces. Cus and Zuperl [1] compared the PSO, GA and SA techniques to estimate the cutting force, the best results were obtained with PSO. Huang et al. [24] studied end-milling process and deployed PSO to minimize tool wear. They took speed, feed rate and width and observed that the memetic PSO (MPSO) algorithm has better performance than back-propagation $\mathrm{NN}$, conventional wavelet neural networks (WNN) and GA-based WNN.

Other works in this area include Zain et al. [25], who studied three parameters of end-milling for minimizing surface roughness. Based on the experimental data, it was concluded that process parameters should be set at the highest cutting speed and the rake angle with the lowest feed in order to obtain the minimum surface roughness. In the area of the face-milling operation, Back et al. [26] studied the effects of the insert run-out errors and the variation of the feed rate on the surface roughness. Thambu et al. 
[27] observed the machining of die cast $\mathrm{Al}$ alloy-SiC composites. Machining studies were conducted on the AlSiC composite work pieces with high-speed steel (HSS) end-mill tools in a milling machine at different speeds and feeds. Dweiri et al. [28] studied the downmilling machining process of Alumic-79 with an adaptive neuro fuzzy inference system to estimate the effect of machining variables, i.e. spindle speed, feed rate, depth of cut and number of flutes on the surface finish. Fuht and $\mathrm{Wu}[29]$ analysed the effect produced by the tool geometries and cutting conditions on the machined surface quality and developed a model predicting the surface quality for aluminium.

\subsection{High Speed Machining}

Most of the researchers used statistical analysis methods in the area of high speed machining. They considered different sets of input parameters, output parameters and tried various analysis techniques based on statistics, including structured equation modelling (SEM) analysis, robust design, and Taguchi design approaches. Kauppinen [30] observed the results of several projects on high-speed milling for testing the suitability of high-speed milling for different kinds of materials. The materials machined were steels, aluminium alloys, graphites and polymer matrix composites. It is observed that most of the materials can be machined by high-speed milling.

Pare et al. [31] conducted experiments varying the speed from 2500 to $7500 \mathrm{rpm}$ on composites. They developed predictive models for surface roughness and used GSA for optimization. In order to determine whether there is uniform variation of surface roughness over speed variation, the range of 5000 to $7500 \mathrm{rpm}$ was taken into consideration. TLBO [32] was used, and the results were studied.

Koshy et al. [33] studied high-speed endmilling of hardened AISI D2 tool steel (58HRC) and estimated surface roughness and tool wear. Ozcelik and Bayramoglu [6] considered the step-over ratio in addition to the three cutting variables and developed a surface roughness prediction model for wet machining conditions. De Souza Jr. et al. [34] examined two facemilling cutter systems in the high-speed cutting of grey cast iron under a determined cutting condition. El-Wahab and Kishawy [35] deployed mathematical models to enhance the surface quality during $\mathrm{CNC}$ machining. Axinte and Dewes [36] observed the experimental results and related empirical models for work piece surface integrity (SI) during high-speed machining.
Ghani et al. [37] implemented Taguchi optimization methodology to optimize cutting parameters, e.g. speed, feed and depth of cut, in endmilling during the machining of hardened steel with a TiN-coated carbide insert tool considering semifinishing and finishing conditions of high-speed milling. The milling parameters used are cutting speed, feed rate and depth of cut. From the analysis of the result, the optimal combination of process parameters for the resultant low cutting force and good surface finish was determined. Arokiadass et al. [2] studied the machining properties of $\mathrm{LM} 25 \mathrm{Al} / \mathrm{SiCp}$ composite in high-speed end-milling. They deployed the RSM and prepared a mathematical model to estimate the high-speed end-milling process parameter.

Some researchers used either soft computing techniques or meta-heuristic techniques for the development of relationships among selected output and input variables. Yong et al. [38] studied highspeed milling processes with the axial depth of cut, radial depth of cut and helical angle as input parameters. They applied GA to estimate cutting force and MRR and achieved very good results. Öktem et al. [7] developed a methodology in order to determine the optimum cutting conditions leading to minimum surface roughness in the milling of mould surfaces, by coupling RSM with a developed GA. RSM was utilized to create an efficient analytical model for surface roughness in terms of cutting parameters: feed, cutting speed, axial depth of cut, radial depth of cut and machining tolerance.

Therefore, there is a need to study in detail how surface roughness varies in wider speed ranges in the case of HSM. There is scope for computing the best machining conditions under high-speed machining for composite materials and applying new heuristic techniques, such as TLBO and GSM, in the area in order to obtain better results. The experimental procedure and results and analysis are explained in subsequent sections.

\section{EXPERIMENTAL PROCEDURE}

The experimental procedure involves four stages: (i) the selection of proper combination of composite material, necessary cutting tools, and required equipment, (ii) data collection by conducting experiments as per the defined plan, (iii) the establishment of a surface roughness prediction model, and (iv) optimization of the predictive model for better results. Each of the stages is explained in the following sub-sections. 


\subsection{Selection of Proper Combination of Composite Material, Cutting Tools and Equipment}

The experimental study was carried out in dry cutting conditions on a high-speed $\mathrm{CNC}$ vertical milling machine (Model-Agni-BMV-45-T-20-Year 2008). Others features are a maximum spindle speed of $10,000 \mathrm{rpm}$, clamping area of $450 \times 900 \mathrm{~mm}^{2}$, feed rate of 1 to $1000 \mu \mathrm{m} / \mathrm{rev}, 15-\mathrm{kW}$ drive motor with a table size of $800 \times 500 \times 550 \mathrm{~mm}^{3}$. The work piece material used was aluminium silicon carbide composite in the form of a $55 \times 55 \times 22 \mathrm{~mm}^{3}$ block. The gravity die-casting method was used for the preparation of Al-SiC material. The hardness of the composite material increased with the increase in the percentage of $\mathrm{SiC}$ in the composite. The percentage of constituents is selected based on experimentation with various combinations of $\mathrm{Al}$ and $\mathrm{SiC}$ and testing the mechanical properties of component. Trial machining is done and the microstructure is also tested before and after trail machining. The material properties of aluminium silicon carbide material are shown in Tables 1 and 2. A flat end mill (25 mm diameter, 451 helix angle, 4-flutes) produced by Addison was used for machining.

Table 1. Chemical composition of (wt \%) Al SiC

\begin{tabular}{cccc}
\hline $\mathrm{Al}$ & $\mathrm{SIC}$ & $\mathrm{Fe}$ & $\mathrm{Co}$ \\
\hline 84.5 & 15.45 & 0.03 & 0.02 \\
\hline
\end{tabular}

Table 2. Mechanical properties of aluminium silicon carbide composite

\begin{tabular}{lcccc}
\hline $\begin{array}{l}\text { Work } \\
\text { material }\end{array}$ & $\begin{array}{c}\text { Tensile } \\
\text { strength }\end{array}$ & Elongation & Density & Hardness \\
\hline $\begin{array}{l}\text { Al SiC } \\
\text { composite }\end{array}$ & $145.32 \mathrm{~N} / \mathrm{mm}^{2}$ & $5.5 \%$ & $2779 \mathrm{~kg} / \mathrm{m}^{3}$ & $63.8 \mathrm{BHN}$ \\
\hline
\end{tabular}

\subsubsection{Microstructure Analysis}

Testing of properties of Al-SiC before machining and micro-structure analysis is one of the methods to study the properties of composites material. A scanning electron microscope is used to observe the microstructure of composite material; after this analysis, various materials used in the composite can easily be observed. To perform the micro-structure analysis, a sample has been cut as per the requirement. Different degrees of fine papers were used to rub the sample starts with $600,800,1000,1200$ and 1500 degrees. Later, it was again rubbed, using a velvet cloth on polishing machine to finally check the microstructure. Etching solution (a mixture of 10 $\mathrm{g} \mathrm{NaOH}, 5 \mathrm{~g}$ of $\mathrm{K} 4(\mathrm{Fe}(\mathrm{CN}) 6)$ and $100 \mathrm{ml}$ distilled water) was used to observe the microstructure of composite.

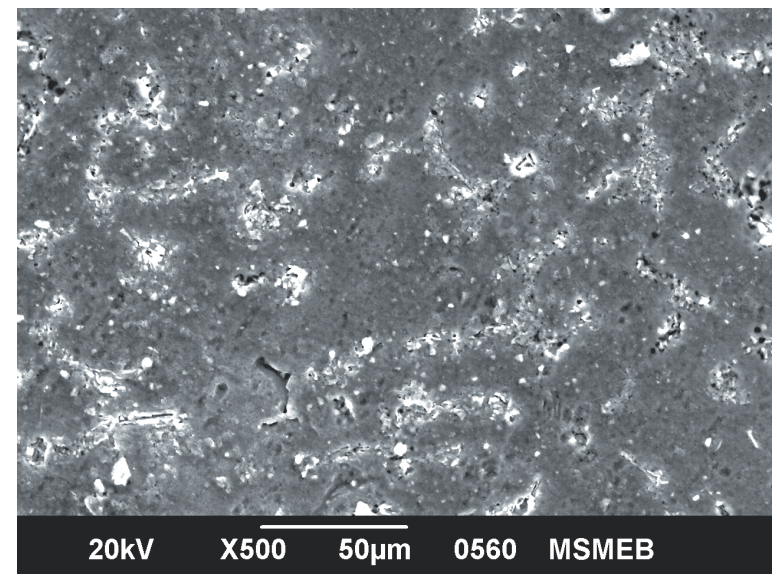

Fig. 1. Micro structure of aluminium silicon carbide composite

This microstructure showed mixing of aluminium and silicon carbide particles in uniform way as shown in Fig. 1. In the microstructure, if particles are segregated near grain boundaries it ideally means that the composite has high hardness; if it is away from grain boundaries, it means it has less hardness. In this case, many particles are going away from grain a boundary, which means that it is highly machinable and very useful for industrial purposes, especially in the aerospace and satellite industries.

\subsubsection{Surface Roughness Measurement}

A portable Surtronic $3+$ was used to measure the surface roughness (shown in Fig. 2). Four readings have been taken in the traverse direction. In case there is a large deviation, extreme values are discarded and additional readings have been taken so that the total number of readings is four.

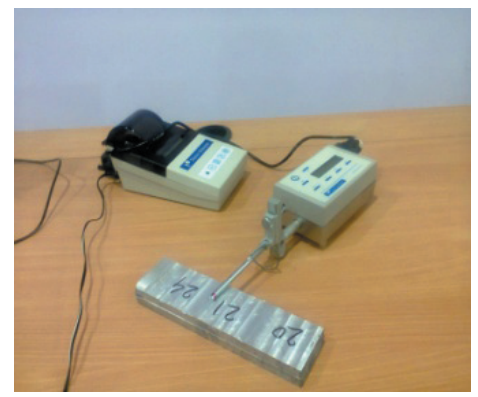

Fig. 2. Surface roughness measurement using Surtronic $3+$

The average value of surface roughness is calculated and recorded. In this study, $R_{a}$ values 
were obtained in the range of 1.25 to $3.50 \mathrm{~mm}$. This variation is significant for aluminium composites in HSM for applications in the aerospace industry. The repeatability of the measurements was found to be in the range of 2 to $5 \%$, which was considered satisfactory for generating empirical models using the variables spindle speed, feed rate, depth of cut and step-over ratio.

\subsection{Collection of Data by Conducting Experiments as per the Plan}

In this study, experimental work was conducted with aluminium silicon carbide composite material on a high-speed CNC milling machine. Five different values of cutting speeds (2000, 3000, 4000, 5000 and $6000 \mathrm{rpm})$ two values for the feed ranging from 100 and $200 \mu \mathrm{m} / \mathrm{rev}$, two values of depth of cut $(0.2$ and $0.4 \mathrm{~mm}$ ), and two values of the step-over ratio (50 and $60 \%$ ), have been taken to conduct the experiments. In this way $(5 \times 2 \times 2 \times 2)$, a total of 40 experiments were designed and conducted in this study and the data is tabulated in Table 5. Five different values are taken for cutting speed, as the range of speed in CNC HSM is very wide. The experiments conducted beyond the $6000 \mathrm{rpm}$ speed range are not presented in this paper, as the variation in surface roughness obtained is marginal.

\subsection{Establishment of Predicted Model for the Selected Output Measure}

A prediction model for surface roughness is established by taking surface roughness as a dependent variable and input variables (cutting speed, depth of cut, feed and step-over ratio) as independent variables. A regression relationship is established between them, and the statistical tests ( $F$-test and $t$-tests) are carried out to test the significance levels. Both linear regression and non-linear regression are attempted.

In linear regression analysis, the general form of equation is:

$$
R_{a}=a_{1} x_{1}+a_{2} x_{2}+a_{3} x_{3}+a_{4} x_{4}+K .
$$

Similarly, general form of non-linear equation is:

$$
R_{a}=K \times x_{1}^{a_{1}} \times x_{2}^{a_{2}} \times x_{3}^{a_{3}} \times x_{4}^{a_{4}}
$$

By taking logarithms on both sides:

$$
\begin{aligned}
\log _{10}\left(R_{a}\right) & =a_{1} \times \log _{10}\left(x_{1}\right)+a_{2} \times \log _{10}\left(x_{2}\right)+ \\
& +a_{3} \times \log _{10}\left(x_{3}\right)+a_{4} \times \log _{10}\left(x_{4}\right)+\log _{10}(K) .
\end{aligned}
$$

In both the above cases, $a_{1}, a_{2}, a_{3}$, and $a_{4}$ are parameters and $x_{1}, x_{2}, x_{3}$, and $x_{4}$ representthe selected input variables of cutting speed, feed, the depth of cut, and the step-over ratio, respectively. $K$ denotes a constant.

\subsection{Optimization of Predictive Model}

The ultimate objective of the optimization process for any problem is to assign values to a set of variables that will result in the best performance of a system. These setting variables can be calculated through deterministic or non-deterministic methods. In the deterministic method, a bottleneck is a local minima and in this regard artificial intelligence optimizing techniques are a better option.

The predictive model obtained in the above subsection is optimized by using four meta-heuristic algorithms (GSA, TLBO, SA and GA) and is explained in the following sub-section as other algorithms are available in the literature. The program code for GSA is developed using MATLAB 2012.

\subsubsection{Gravitational Search Algorithm}

The concept of algorithm is as follows: the performance of the agents that are considered as the objects is calculated by their masses. As in space, all these objects are attracted to each other because of gravitational force, and a shifting of smaller masses towards heavier masses takes place. The heavier masses, due to weight, change their positions more slowly in comparison to lighter ones. There can be four classifications for the masses: active, passive, inertial mass and position. A correlation can be established as the position of the masses, and the solution of the problem is similar. A fitness function is applied to determine its gravitational and inertial masses.

The GSA is governed by two laws: (i) the law of gravity, and (ii) the law of motion. According to law of gravity, every point mass in the universe attracts every other point mass with a force that is directly proportional to the product of their masses and inversely proportional to the square of the distance between them [8]. The law of motion states that the current velocity of any mass will be equal to the sum of the fraction of its previous velocity and the variation within the velocity. Variation in the velocity of any mass is equal to the force acted on the system divided by mass of inertia. The different steps of the GSA are as follows:

- The first population is initialized to start. 
- The fitness of each agent is evaluated and values are recorded.

- $G$ is updated and the best and worst fitness rates in the population for $i=1,2, \ldots, N$ are selected.

- $M$ (weighting in range $[0,1]$ ) is updated. Then update $K_{\text {best }}$ and calculate $F$. Then update $a$.

- The velocity and the position are updated: All positions should be in a feasible range.

- Repeat steps 2 to 5 until the stop criteria.

- End.

The following parameters must be set in GSA:

- $\quad$ Population size, $N$ : the number of agents.

- Dimension, $D$ : The control variables number.

- Maximum iteration, $T$ : number of iterations to stop the optimization process if there is no convergence.

- Initial gravity, $G_{0}$ : initial value of gravity, $G$.

GSA is a memory-less algorithm and very effective in most types of optimization problems.

\section{RESULTS AND DISCUSSIONS}

The microstructure of the composite material of the selected combination showed no significant difference before and after machining, thus indicating the material is stable over the selected range of speed variation. The microstructure after machining is shown in Fig. 3. In this paper, linear and non-linear relationships were established between input and output parameters to predict surface roughness. Four heuristic methods (GA, SA, TLBO and GSA) are used for optimization.

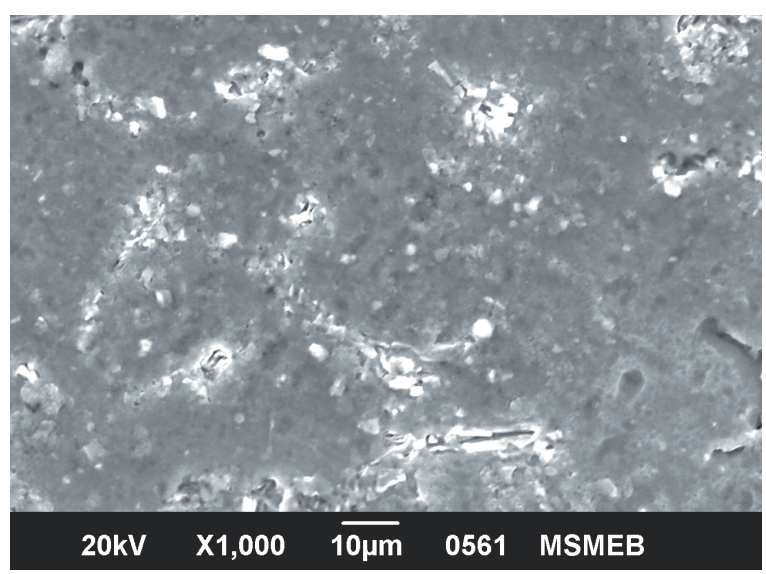

Fig. 3 Micro-structure of aluminium silicon carbide composite

All these four techniques are fundamentally different from each other: GA is based upon the survival of fittest, SA is based upon annealing, TLBO is inspired by the teaching-learning method and GSA is inspired by natural phenomenon of gravitational law. It is important to compare the result of these techniques so as to select the best technique for this case.

Table 3. Selected input parameter

\begin{tabular}{lcc}
\hline Parameter & Smallest value & Largest value \\
\hline Speed $\left(x_{1}\right)[\mathrm{m} / \mathrm{min}]$ & 2000 & 6000 \\
\hline Feed $\left(x_{2}\right)[\mu \mathrm{m} / \mathrm{rev}]$ & 100 & 200 \\
\hline Depth of cut $\left(x_{3}\right)[\mathrm{mm}]$ & 0.2 & 0.4 \\
\hline Step-over ratio $\left(x_{4}\right)$ & 0.5 & 0.6 \\
\hline
\end{tabular}

MATLAB 2012 was used for preparation of codes. The ranges taken for conducting experiments with the selected input variables are given in Table 3. The smallest value is taken as $2000 \mathrm{rpm}$ for the cutting speed, as the lower speed values are covered in the case of conventional machines by earlier researchers for this case. Based on the selected range, experiments were conducted on a high-speed CNC machine, and data was collected by varying the cutting speed, feed, and depth of cut and step-over ratio while machining the Al-SiC composite material. In this experiment, coolant was not used and other indirect factors (machine vibration, machine tolerance, and operator performance) are assumed to be insignificant. The combinations of input variables and the measured output variable are given in Table 4.

Table 4. Experimental data

\begin{tabular}{|c|c|c|c|c|c|c|c|c|c|c|c|}
\hline $\begin{array}{l}\text { S. } \\
\text { no }\end{array}$ & $x_{1}$ & $x_{2}$ & $x_{3}$ & $x_{4}$ & $R_{a}$ & $\begin{array}{l}\text { S. } \\
\text { no }\end{array}$ & $x_{1}$ & $x_{2}$ & $x_{3}$ & $x_{4}$ & $R_{a}$ \\
\hline 1 & 2000 & 100 & 0.2 & 0.5 & 2.30 & 21 & 4000 & 200 & 0.2 & 0.5 & 2.10 \\
\hline 2 & 2000 & 100 & 0.2 & 0.6 & 3.03 & 22 & 4000 & 200 & 0.2 & 0.6 & 2.46 \\
\hline 3 & 2000 & 100 & 0.4 & 0.5 & 2.62 & 23 & 4000 & 200 & 0.4 & 0.5 & 2.34 \\
\hline 4 & 2000 & 100 & 0.4 & 0.6 & 3.13 & 24 & 4000 & 200 & 0.4 & 0.6 & 2.65 \\
\hline 5 & 2000 & 200 & 0.2 & 0.5 & 2.65 & 25 & 5000 & 100 & 0.2 & 0.5 & 1.45 \\
\hline 6 & 2000 & 200 & 0.2 & 0.6 & 3.18 & 26 & 5000 & 100 & 0.2 & 0.6 & 1.63 \\
\hline 7 & 2000 & 200 & 0.4 & 0.5 & 2.95 & 27 & 5000 & 100 & 0.4 & 0.5 & 1.51 \\
\hline 8 & 2000 & 200 & 0.4 & 0.6 & 3.25 & 28 & 5000 & 100 & 0.4 & 0.6 & 1.79 \\
\hline 9 & 3000 & 100 & 0.2 & 0.5 & 2.15 & 29 & 5000 & 200 & 0.2 & 0.5 & 1.48 \\
\hline 10 & 3000 & 100 & 0.2 & 0.6 & 2.51 & 30 & 5000 & 200 & 0.2 & 0.6 & 1.60 \\
\hline 11 & 3000 & 100 & 0.4 & 0.5 & 2.45 & 31 & 5000 & 200 & 0.4 & 0.5 & 1.88 \\
\hline 12 & 3000 & 100 & 0.4 & 0.6 & 2.90 & 32 & 5000 & 200 & 0.4 & 0.6 & 1.99 \\
\hline 13 & 3000 & 200 & 0.2 & 0.5 & 2.26 & 33 & 6000 & 100 & 0.2 & 0.5 & 1.62 \\
\hline 14 & 3000 & 200 & 0.2 & 0.6 & 2.63 & 34 & 6000 & 100 & 0.2 & 0.6 & 1.69 \\
\hline 15 & 3000 & 200 & 0.4 & 0.5 & 2.54 & 35 & 6000 & 100 & 0.4 & 0.5 & 1.74 \\
\hline 16 & 3000 & 200 & 0.4 & 0.6 & 3.02 & 36 & 6000 & 100 & 0.4 & 0.6 & 2.10 \\
\hline 17 & 4000 & 100 & 0.2 & 0.5 & 1.98 & 37 & 6000 & 200 & 0.2 & 0.5 & 1.91 \\
\hline 18 & 4000 & 100 & 0.2 & 0.6 & 2.24 & 38 & 6000 & 200 & 0.2 & 0.6 & 2.19 \\
\hline 19 & 4000 & 100 & 0.4 & 0.5 & 2.20 & 39 & 6000 & 200 & 0.4 & 0.5 & 1.93 \\
\hline 20 & 4000 & 100 & 0.4 & 0.6 & 2.54 & 40 & 6000 & 200 & 0.4 & 0.6 & 2.30 \\
\hline
\end{tabular}


The regression equation, which relates the dependent variable, surface roughness and independent variables as given in Table 1, is given in Eq. (4).

$$
\begin{aligned}
R_{a} & =0.893-0.00028 x_{1}+0.00186 x_{2}+ \\
& +1.19 x_{3}+3.39 x_{4} .
\end{aligned}
$$

In this analysis, $p$ values are close to zero and the $F$ value is 43.77 which are considered a good fit between the dependent and independent variables. Similarly, with the help of MINITAB software based on the same 40 experimental data points, a non-linear regression equation was developed, given in Eq. (5).

\subsection{Linear Regression Analysis}

For linear regression analysis and an associated statistical test to calculate a $p$ value, for the coefficients associated with each independent variable, the MINITAB software package is used.

$$
\begin{aligned}
\log _{10}\left(R_{a}\right) & =1.99-0.454 \log _{10}\left(x_{1}\right)+0.124 \log _{10}\left(x_{2}\right)+ \\
& +0.157 \log _{10}\left(x_{3}\right)+0.794 \log _{10}\left(x_{4}\right) .
\end{aligned}
$$

Table 5a. Results of test of significance of independent variables - linear regression

\begin{tabular}{lcccc}
\hline Predictor & Coef & SE Coef & $t$ & $P$ \\
\hline Constant & 0.8925 & 0.4195 & 2.13 & 0.041 \\
\hline$v$ & -.0002799 & 0.0000244 & -11.48 & 0.00 \\
\hline$f$ & .0018650 & 0.0006897 & 2.70 & .011 \\
\hline$d$ & 1.1925 & 0.3449 & 3.46 & .001 \\
\hline$s r$ & 3.3850 & 0.6897 & 4.91 & 0.00 \\
\hline \multicolumn{5}{c}{$\mathrm{S}=0.218111 \mathrm{R}-\mathrm{Sq}=83.3 \% \mathrm{R}-\mathrm{Sq}(\mathrm{adj})=81.4 \%$} \\
\hline
\end{tabular}

Table 5b. Results of analysis of variance

\begin{tabular}{lccccc}
\hline Source & DF & SS & MSE & $F$ value & $P$ value \\
\hline Regression & 4 & 8.3289 & 2.0822 & 43.77 & 0.00 \\
\hline Residual error & 35 & 1.6650 & 0.0476 & & \\
\hline Total & 39 & 9.9939 & & & \\
\hline
\end{tabular}

In Table 5a, the associated variable is an effective and efficient predictor. The $R^{2}$ value in statics also is key parameter because it indicates model performance. In this case, the $R^{2}$ value is $81.4 \%$ and this model explains $81.4 \%$ of the variation in the dependent variable. In Table $5 \mathrm{~b}$, residual errors are the unexplained portion of the dependent variable; a large residual error means model is unfit but in this case residual error is not too much so this model is fit for prediction. The results suggest that all the four input parameters have significant effects on surface roughness.

\subsection{Non-Linear Regression Analysis}

In this study, non-linear regression analysis is performed with experimental data. In Table 6 , the test of significance and variance, $p$ value is 0.01 , so it is statistically significant at a $99 \%$ confidence level, and the associated variable is an effective and efficient predictor. Standard error estimates are very low for all four parameters, which indicates that this model is fit for prediction of surface roughness. The coefficients of non-linear regression equation clearly indicate that the effect of all the process parameters is significant on the surface roughness.

Table 6a. Results of test of significance -non-linear regression

\begin{tabular}{lcccc}
\hline Predictor & Coef & SE Coef & $t$ & $P$ \\
\hline Constant & 1.9944 & 0.1876 & 10.63 & 0.000 \\
\hline$v$ & -0.4542 & 0.04174 & -10.88 & 0.000 \\
\hline$f$ & 0.1242 & 0.04673 & 2.66 & 0.012 \\
\hline$d$ & 0.1569 & 0.04673 & 3.36 & 0.002 \\
\hline$s r$ & 0.7940 & 0.1776 & 4.47 & 0.000 \\
\hline \multicolumn{4}{c}{$\mathrm{S}=0.0444809 \mathrm{R}-\mathrm{Sq}=81.7 \% \mathrm{R}-\mathrm{Sq}(\mathrm{adj})=79.7 \%$} \\
\hline
\end{tabular}

Table 6b. Results of analysis of variance - linear regression

\begin{tabular}{lccccc}
\hline Source & DF & SS & MSE & $F$ value & $P$ value \\
\hline Regre-ssion & 4 & 0.310046 & 0.0775 & 39.18 & 0.00 \\
\hline Residual error & 35 & 0.069249 & 0.00198 & & \\
\hline Total & 39 & 0.379295 & & & \\
\hline
\end{tabular}

\subsection{Optimization Using Selected Heuristic Methods}

After developing the relationships between dependent and independent variables using linear and non-linear regression methods, four optimization techniques were used, as explained earlier, and the results are given in Tables 7 and 8 for linear and non-linear relations, respectively.

The results obtained using the four selected techniques reveal that higher speed is desirable in order to obtain a minimum surface roughness value. In the case of feed rate, the values varied from 101.56 to $192.3 \mu \mathrm{m} / \mathrm{rev}$; only one value was close to 200 and other three values were close to $100 \mu \mathrm{m} / \mathrm{rev}$, indicating that the low value of feed is desirable for minimum surface roughness. In the case of depth of cut, three values are close to $0.2 \mathrm{~mm}$, indicating that a low value of depth of cut is desirable for minimum surface roughness. The step-over ratio varies from 0.5 to 0.6 , three values are close to 0.5 , and one value is close to 0.6 . As the number of iterations is greater in 
the case of SA and GSA, it may be concluded that a step-over ratio of 0.5 is desirable for further work.

Table 7. Comparison of four selected optimization methods - linear regression (LR)

\begin{tabular}{lcccc}
\hline Parameter & GA & SA & TLB0 & GSA \\
\hline$x_{1}$ & 5702.37 & 2238.07 & 5950.2 & 5739.88 \\
\hline$x_{2}$ & 147.026 & 101.564 & 192.3 & 105.357 \\
\hline$x_{3}$ & 0.24049 & 0.2 & 0.3 & 0.237 \\
\hline$x_{4}$ & 0.5067 & 0.6 & 0.5 & 0.5224 \\
\hline$R_{a}[\mu \mathrm{m}]$ & 1.57 & 2.389 & 1.63 & 1.53 \\
\hline Iteration & 51 & 6307 & 5 & 1000 \\
\hline
\end{tabular}

Table 8. Comparison of four selected optimization methods - nonlinear regression (NLR)

\begin{tabular}{lcccc}
\hline Parameter & GA & SA & TLB0 & GSA \\
\hline$x_{1}$ & 5127.23 & 2846.235 & 4677.3 & 5984.9 \\
\hline$x_{2}$ & 102.467 & 102.434 & 161.2 & 124.71 \\
\hline$x_{3}$ & 0.2 & 0.2 & 0.3 & 0.216 \\
\hline$x_{4}$ & 0.519 & .5 & 0.5 & 0.5074 \\
\hline$R_{a}[\mu \mathrm{m}]$ & 1.66 & 2.09 & 1.88 & 1.571 \\
\hline Iteration & 59 & 5953 & 5 & 1000 \\
\hline
\end{tabular}

From the analysis for non-linear relationship, it was observed from the Table 8 that cutting speed varies from 2846.24 to $5984.9 \mathrm{rpm}$, indicating that higher speed is desirable for minimum surface roughness. Similarly, a lower value of feed, a lower value of depth of cut and a $50 \%$ step-over ratio is required for minimum surface roughness. From Tables 7 and 8, GSA gives the minimum value of surface roughness as compared to other selected techniques. Therefore, it may be concluded that GSA is very effective in comparison to other techniques.

\subsection{Validation of Results}

For validation purposes, four separate experiments were conducted, and the data were recorded. The value of surface roughness is computed using Eqs. (4) and (5). The results are presented in Tables 9 and 10. It is observed that the maximum percentage of error was $-12.0 \%$ and thus the results are validated. From results, it is clear that the non-linear regression equation better describes the data, as the range of percentage error is 10.1 as compared to range of percentage error of $16.01 \%$ in the case of linear regression relation. Therefore, Eq. (5) fits the data better as far as validation results and best fit tests are concerned.
Table 9. Validation of results for $L R$

\begin{tabular}{|c|c|c|c|c|c|c|c|}
\hline$x_{1}$ & $x_{2}$ & $x_{3}$ & $x_{4}$ & 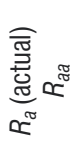 & 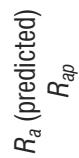 & 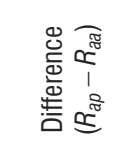 & $\begin{array}{l}\frac{8}{\times} \\
\frac{1}{\frac{1}{2}} \\
\frac{1}{4}\end{array}$ \\
\hline 3000 & 150 & 0.4 & 0.6 & 2.82 & 2.842 & 0.022 & 0.7 \\
\hline 4000 & 150 & 0.4 & 0.5 & 2.14 & 2.223 & 0.0 .083 & 3.73 \\
\hline 6000 & 150 & 0.2 & 0.6 & 1.60 & 1.425 & -0.175 & -12.28 \\
\hline 6000 & 150 & 0.4 & 0.5 & 1.75 & 1.663 & -0.090155 & -5.2 \\
\hline
\end{tabular}

Table 10. Validation of results for NLR

\begin{tabular}{|c|c|c|c|c|c|c|c|}
\hline$x_{1}$ & $x_{2}$ & $x_{3}$ & $x_{4}$ & 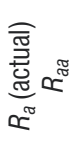 & 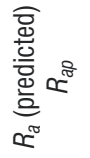 & 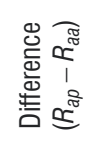 & $\begin{array}{l}\text { 음 } \\
\text { 홍 } \\
\text { 흔 }\end{array}$ \\
\hline 3000 & 150 & 0.4 & 0.6 & 2.82 & 2.77 & -0.05 & -1.8 \\
\hline 4000 & 150 & 0.4 & 0.5 & 2.14 & 2.10 & -0.04 & -1.9 \\
\hline 6000 & 150 & 0.2 & 0.6 & 1.60 & 1.814 & +0.214 & 11.7 \\
\hline 6000 & 150 & 0.4 & 0.5 & 1.75 & 1.75 & 0.00 & 0 \\
\hline
\end{tabular}

\section{CONCLUSIONS}

In this research, the microstructure of $\mathrm{Al} \mathrm{SiC}$ composite is found to be stable after testing it before and after machining in HSM. The surface roughness models after optimization using four meta-heuristic techniques reveal that GSA proved to be the best among the four techniques in terms of optimum value of surface roughness and that TLBO gave better result in terms of number of iterations. The non-linear regression equation better explains the relationship between surface roughness and input parameters. This study can be a basis for future researchers as more input parameters need to be taken into consideration in order to predict the surface roughness at much higher speeds, i.e. of $6000 \mathrm{rpm}$ onwards. The interaction effects, if any, can also be studied by future researchers. There is a scope to consider more such composite materials with various combinations of constituent materials under high-speed cutting conditions in order to compute the optimum values of input machining conditions for better design of manufacturing processes.

\section{REFERENCES}

[1] Cus, F., Zuperl. (2007). Particle swarm intelligence based optimization of high speed end milling. Journal of Achievements in Materials and Manufacturing Engineering, vol. 22, no. 2, p. 75-78.

[2] Arokiadass, R., Palaniradja, K., Alagumoorthi, N. (2012). Prediction and optimization of end milling process parameters 
of cast aluminium based MMC. Transactions of Nonferrous Metals Society of China, vol. 22, no. 7, p. 1568-1574, D0I:10.1016/S1003-6326(11)61357-5.

[3] Palanikumar, K., Karthikeyan, R. (2007). Assessment of factors influencing surface roughness on the machining of Al/ SiC particulate composites. Materials and Design, vol. 28, no. 5, p. 1584-1591, D0l:10.1016/j.matdes.2006.02.010.

[4] Pathak, J.P., Singh, J.K., Mohan, S. (2006). Sythensis and characterization of aluminium silicon carbide composite. Indian Journal of Engineering \& Material Science, vol. 13, no. 3, p. 238-246.

[5] Rao, R.V., Savsani, V.J., Vakharia, D.P. (2012). Teachinglearning based optimization: an optimization method for continuous non-linear large scale problems. Information Science, vol. 183, no. 1, p. 1-15, D0l:10.1016/j. ins.2011.08.006.

[6] Ozcelik, B., Bayramoglu, M. (2006). The statistical modeling of surface roughness in high-speed flat end milling. International Journal of Machine Tools \& Manufacturing, vol. 46, no. 12-13, p. 1395-1402, D0l:10.1016/j.ijmachtools.2005.10.005.

[7] Öktem, H., Erzurumlu, T., Kurtaran, H. (2005). Application of response surface methodology in the optimization of cutting conditions for surface roughness. Journal of Material Processing Technology, vol. 170, no. 1-2, p. 11-16, D0I:10.1016/J.jmatprotec.2005.04.096.

[8] Rashedi, E., Nezamabadi-pour, H., Saryazdi, S. (2009). GSA: A gravitational search algorithm. Information Sciences, vol. 179, no.13, p. 2232-2248, DOl:10.1016/j.ins.2009.03.004.

[9] Rao, R.V., Savsani V.J., Vakharia, D.P. (2011). Teachinglearning-based optimization: A novel method for constrained mechanical design optimization problems. Computer Aided Design, vol. 43, no. 3, p. 303-315, D0l:10.1016/j. cad.2010.12.015.

[10] Neelima Devi, C., Mahesh, V., Selvaraj, N. (2011). Mechanical characterization of aluminium silicon carbide composite. International Journal of Applied Engineering Research, vol. 1, no. 4, p. 793-799.

[11] Dabade, U.V., Joshi, S.S., Balasubramaniam, R., Bhanuprasad, V.V. (2007). Surface finish and integrity of machined surfaces on Al/SiCp composites. Journal of Materials Processing Technology, vol. 192-193, p. 166-174, D0l:10.1016/j. jmatprotec.2007.04.044.

[12] Basheer, A.C., Dabade, U.V., Joshi, S.S. (2008). Modeling of surface roughness in precision machining of metal matrix composites using ANN. Journal of Materials Processing Technology, vol. 197, no. 1-3, p. 439-444, D0l:10.1016/j. jmatprotec.2007.04.121.

[13] Seeman, M., Ganesan, G., Karthikeyan, R., Velayudham, A. (2010). Study on tool wear and surface roughness in machining of particulate aluminium metal matrix compositeresponse surface methodology approach. The International Journal of Advanced Manufacturing Technology, vol. 48, no. 5-8, p. 613-624, Dol:10.1007/s00170-009-2297-z.

[14] Bhushan, R.K., Kumar, S., Das, S. (2012). GA approach for optimization of surface roughness parameters in machining of Al alloy SiC particle composite. Journal of Materials Engineering and Performance, vol. 21, no. 8, p. 1676-1686, DOI:10.1007/s1665-011-0066-2.
[15] Rai, J.K., Brand, D., Slama, M., Xirouchakis, P. (2011). Optimal selection of cutting parameters in multi-tool milling operations using a genetic algorithm. International Journal of Production Research, vol. 49, no. 10, p. 3045-3068, Dol:10.1080/00207540903382873.

[16] Del Prete, A., De Vitis, A.A., Anglani, A. (2010). Roughness improvement in machining operations through coupled meta model and genetic algorithms technique. International Journal of Material Forming, vol. 3, no. 1, p. 467-470, D0l:10.1007/ s12289-010-0808-y.

[17] Xu, F., Zhu, J.J., Wu, X., Zang, X.J., Zuo, D. W. (2010). Parameter optimization of milling Ti6Al4V using GA approach. Key Engineering Materials, vol. 426-427, p. 1-4, D0I:10.4028/ www.scientific.net/KEM.426-427.1.

[18] Saffar, R.J., Razfar, M.R. (2010). Simulation of end milling operation for predicting cutting forces to minimize tool deflection by genetic algorithm. Machining Science and Technology, vol. 14, no. 1, p. 81-101, DOI:10.1080/10910340903586483.

[19] Alam, S., Nurul Amin, A.K.M., Patwari, A. U., Konneh, M. (2010). Prediction and investigation of surface response in high speed end milling of Ti-6Al-4V and optimization by genetic algorithm. Advanced Materials Research, vol. 83-86, p. 10091015, DOI:10.4028/www.scientific.net/AMR.83-86.1009.

[20] Li, J.G., Yao, Y.X., Gao, D., Liu, C.Q., Yuan, Z.J. (2008). Cutting parameters optimization by using particle swarm optimization (PSO). Applied Mechanics and Materials, vol. 10-12, p. 879883.

[21] Pare, V., Agnihotri, G., Krishna, C.M. (2011). Optimization of cutting condition in end milling process with the approach of particle swarm optimization. International Journal of Mechanical and Industrial Engineering, vol. 1, no. 2, p. 22316477.

[22] Zubaidi, S.A., Ghani, J.A., Haron, C.H.C. (2013). Optimization of cutting conditions for end milling of Ti6AI4V alloy by using a gravitational search algorithm (GSA). Meccanica, vol. 48, no. 7, p. 1701-1715, Dol:10.1007/s11012-013-9702-2.

[23] Farahnakian, M., Razfar, M.R., Moghri, M., Asadnia, M. (2011). The selection of milling parameters by the PSO-based neural network modeling method. The International Journal of Advanced Manufacturing Technology, vol. 57, no. 1-4, p. 4960, D0I:10.1007/s00170-011-3262-1.

[24] Huang, H., Li, A., Lin, X. (2007).Application of PSO-based wavelet neural network in tool wear monitoring. Proceedings of the IEEE International Conference on Automation and Logistics, p. 2813-2817, D0l:10.1109/ICAL.2007.4339060.

[25] Zain, A.M., Haron, H., Sharif, S. (2011). Integration of simulated annealing and genetic algorithm to estimate optimal solutions for minimizing surface roughness in end milling Ti-6AL-4V. International Journal of Computer Integrated Manufacturing, vol. 24, no. 6, p. 574-592, D0l:10.1080/095 1192X.2011.566629.

[26] Baek, D.K., Ko, T.J., Kim, H.S. (2001). Optimization of feed rate in a face milling operation using a surface roughness model. International Journal of Machine Tools \& Manufacturing, vol. 41, no. 3, p. 451-462, Dol:10.1016/S0890-6955(00)00039-0.

[27] Thambu, S., Marimuthu, K. (2010). Machining studies of die cast aluminium alloy-silicon carbide composites. International 
Journal of Minerals, Metallurgy and Materials, vol. 17, no. 5, p. 648-653, DOI:10.1007/s12613-010-0369-6.

[28] Dweiri, F., Al-Jarrah, M., Al Wedyan, H. (2003). Fuzzy surface roughness modeling of CNC down milling of Alumin-79. Journal of Materials Processing Technology, vol. 133, no. 3, p. 266-275, DOl:10.1016/S0924-0136(02)00847-6.

[29] Fuht, K.H., Wu, C.F. (1995). A proposed statistical model for surface quality prediction in end-milling of Al alloy. International Journal of Machine Tools and Manufacturing, vol. 35, no. 8, p. 1187-1200, DOl:10.1016/0890-6955(95)90408-E.

[30] Kauppinen, V. (2004). High speed milling - a new manufacturing technology. $4^{\text {th }}$ International DAAAM Conference on Industrial Engineering Innovation as Competitive Edge for SME, p. 131-134.

[31] Pare, V., Agnihotri, G., Krishna, C.M. (2013). Optimization of machining parameters in high speed end milling of Al-SiC using gravitational search algorithm. International Journal of Recent Advances in Mechanical Engineering, vol. 2, no. 4, p. 45-51.

[32] Pare, V., Agnihotri, G., Krishna, C.M. (2013). Optimization of machining parameters in high speed end milling of Al-SiC composites using teaching learning based optimization. Proceedings of the $2^{\text {nd }}$ International Conference on Intelligent Robotics, Automation and Manufacturing, p. 522-528.

[33] Koshy, P., Dewes, R.C., Aspinwall, D.K. (2002). High speed end milling of hardened AISI D2 tool steel (58 HRC). Journal of
Materials Processing Technology, vol. 127, no. 2, p. 266-273, D0I:10.1016/S0924-0136(02)00155-3.

[34] De Souza Jr., A.M., Sales, W.F., Santos, S.C., Machado, A.R. (2005). Performance of single Si3N4 and mixed Si3N4CPCBN wiper cutting tools applied to high speed face milling of cast iron. International Journal of Machine Tools \& Manufacture, vol. 45, no. 3, p. 335-344, D0l:10.1016/j. ijmachtools.2004.08.006.

[35] El-Wahab, A.I., Kishawy, H.A. (2000). A new method to improve the surface quality during CNC machining. International Journal of Production Research, vol. 38, no. 16, p. 3711-3723, DOI:10.1080/00207540050175969.

[36] Axinte, D.A., Dewes, R.C. (2002). Surface integrity of hot work tool steel after high speed milling-experimental data and empirical models. Journal of Materials Processing Technology, vol. 127, no. 3, p. 325-335, D0l:10.1016/S09240136(02)00282-0.

[37] Ghani, J.A., Choudhury, I.A. Hassan, H.H., (2004). Application of Taguchi method in the optimization of milling of Al alloy. Journal of Materials Processing Technology, vol. 145, no. 1, p. 84-92, D0I:10.1016/S0924-0136(03)00865-3.

[38] Yong, Z.P., Jun, Z., Xiuli, F., Xing, A. (2010). Optimization of surface roughness based on multi-linear regression model and genetic algorithm. Advanced Materials Research, vol. 97101, p. 3050-3054, D0l:10.4028/www.scientific.net/AMR.97101.3050. 